Documenta \& Instrumenta

ISSN-e: 1697-3798

http://dx.doi.org/10.5209/DOCU.64064

\title{
Proyectar el poder real en una fundación regia. Los sellos en tinta de las Nuevas Poblaciones de Sierra Morena y Andalucía
}

Francisco José Pérez Fernández ${ }^{1}$; Adolfo Hamer Flores ${ }^{2}$

Recibido: 22 de octubre de 2018 / Aceptado: 3 de abril de 2019

Resumen. El presente artículo realiza el estudio de los sellos en tinta utilizados en la Intendencia de las Nuevas Poblaciones de Sierra Morena y Andalucía, hasta la fecha completamente ignorados por la historiografía. Durante la Década Absolutista, coincidiendo con el gobierno de Pedro Polo de Alcocer, la documentación administrativa de esta Intendencia empezó a mostrar las improntas de varios sellos en los que era visible su carácter de jurisdicción real e incluso de colonización agraria.

Palabras clave. Poder; sello; símbolos reales; Pedro Polo de Alcocer; siglo XIX.

\section{[en] Projecting royal power in a royal foundation. The ink stamps of the Nue-} vas Poblaciones de Sierra Morena y Andalucía

\begin{abstract}
The present article studies of the ink stamps used in the Intendance of the Nuevas Poblaciones de Sierra Morena y Andalucía, to date completely ignored by the historiography. During the Absolutist Decade, coinciding with the government of Pedro Polo de Alcocer, the administrative documentation of this Intendancy began to show the imprints of several stamps in which its character of real jurisdiction and even of agrarian colonization became visible.
\end{abstract}

Keywords. Power; stamp; royal symbols; Pedro Polo de Alcocer; 19th century.

Sumario. 1. Introducción. 2. Las Nuevas Poblaciones de Sierra Morena y Andalucía: una fundación real. 3. Los sellos en tinta utilizados en las Nuevas Poblaciones de Sierra Morena y Andalucía. 4. Conclusiones.

Cómo citar: F. J. Pérez Fernández y A. Hamer Flores, "Proyectar el poder real en una fundación regia. Los sellos en tinta de las Nuevas Poblaciones de Sierra Morena y Andalucía", Documenta \& Instrumenta, 17 (2019), pp. 113-125.

1 Universidad de Jaén (España)

E-mail: fjperezfdez@telefonica.net

2 Universidad Loyola Andalucía (España)

E-mail: ahamer@uloyola.es 


\section{Introducción}

El uso de los sellos en tinta por parte de la administración provincial y, sobre todo, local no se generalizó en nuestro país hasta la segunda mitad del siglo XIX. La orden del Ministerio de la Gobernación de 16 de julio de 1840 es la primera que aspiraba a que todas las corporaciones municipales tuviesen su propio escudo de armas ${ }^{3}$. No obstante, el cumplimiento de las disposiciones gubernativas ajenas a temáticas de hacienda o militar no era entonces mayoritario, de ahí la necesidad de reiterar las mismas disposiciones en sucesivas órdenes. Este fue el caso, por ejemplo, de la real orden de 28 de abril de 1848, en la que la reina Isabel II resolvió que aquellos ayuntamientos que no lo poseyesen entonces lo adquiriesen inmediatamente. Su propósito era muy concreto, pero contribuiría a su difusión pues se utilizaban en la autorización de certificaciones que presentaban los miembros deslocalizados del ejército que, no pudiendo incorporarse a sus cuerpos, pasaban revista ante los alcaldes de los pueblos. El motivo principal era que existiera un elemento validatorio que evitase falsificaciones por la falta de conocimiento que había en otros organismos de los nombres y firmas con que se autorizaban esos documentos ${ }^{4}$.

Durante la Edad Moderna el uso de sellos en tinta, e incluso en placa, se redujo considerablemente frente a la época medieval a pesar de que la utilización del papel como soporte de escritura hacía perfectamente factible su uso. De este modo, frente a una etapa medieval en la que predominaba el sellado de pergaminos, se pasó a otra en la que este mecanismo de validación se redujo considerablemente. Una realidad a la que también contribuyó la introducción del papel sellado y la propia realidad de que los elementos heráldicos se trasladasen a otros soportes y espacios más allá del documental. Así pues, el uso de los sellos quedó reducido a nivel local a parte de la nobleza señorial, a algunas entidades religiosas y a las autoridades municipales de localidades de cierta importancia o que las mantuvieron desde la Edad Media ${ }^{5}$. Firmas, rúbricas y signos fueron suficientes para validar buena parte de la documentación.

En el caso concreto que aquí analizaremos, la Intendencia de las Nuevas Poblaciones de Sierra Morena y Andalucía, no puede hablarse de pervivencia de símbolos medievales ni de jurisdicciones señoriales o eclesiásticas debido a que fue establecida por la monarquía durante el reinado de Carlos III. Nos hallamos, pues, ante una fundación real que tuvo su inicio en 1767, momento en el que a través de una serie de disposiciones, entre las que destaca la Instrucción y Fuero de Población publicada el 5 de julio de ese año, se puso en marcha esta nueva jurisdicción con territorios segregados a los reinos de Jaén, Córdoba, Sevilla y la provincia de La Mancha.

3 V. de CADENAS Y VICENT, Fundamentos de Heráldica (ciencia del blasón), Madrid, 1994, p. 93. La orden ministerial de 30 de agosto de 1876, por la que se formó la colección sigilográfica municipal conservada hoy en el Archivo Histórico Nacional, tenía como uno de sus objetivos el comprobar el grado de cumplimiento de la orden de 1840 .

4 Colección legislativa de España (continuación de la colección de decretos). Primer cuatrimestre de 1848. Tomo XLIII, Madrid, 1849, pp. 504-505.

5 J. J. ANTEQUERA LUENGO, Heráldica Oficial de la provincia de Córdoba, Sevilla, 2007, pp. 251-253. 
Durante décadas, en la documentación de gobierno y administración de estas Nuevas Poblaciones no se empleó ningún tipo de sello propio ${ }^{6}$, pero durante la última etapa de vigencia del absolutismo en nuestro país se constata en ellas el uso de varios sellos en tinta de este tipo. Un hecho que, hasta la fecha, no ha sido analizado y ni tan siquiera mencionado en la historiografía disponible.

Nuestro objetivo aquí, por tanto, será el de dar a conocer y analizar el uso de sellos en tinta en la Intendencia de las Nuevas Poblaciones de Sierra Morena y Andalucía durante la Década Absolutista. Una labor que consideramos necesaria para la adecuada comprensión de las estrategias empleadas por los gobernantes de esta jurisdicción en sus planes de reivindicación de su autonomía y su régimen foral en un contexto constitucionalista que había apostado en varias ocasiones por su supresión. El trágico devenir de la documentación de esta etapa en los archivos vinculados con esta colonización agraria ha hecho que en nuestros días el volumen documental conservado no sea muy amplio, inconveniente que hemos tratado de minimizar con la consulta de todos los archivos que nos consta que han conservado fondos en nuestros días. El resultado, a nuestro juicio, ha sido muy satisfactorio ya que nos ha sido posible alcanzar novedosas conclusiones y establecer cronologías bastante precisas en el tema analizado.

\section{Las Nuevas Poblaciones de Sierra Morena y Andalucía: una fundación real}

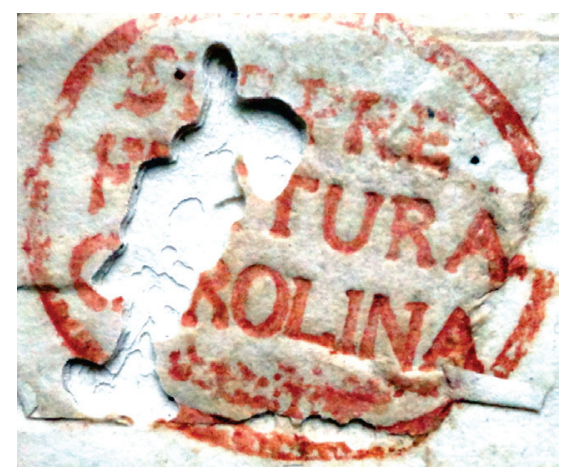

Figura 1. Sello en tinta de la Subprefectura de La Carolina, año 1811 (AMA, caja 20).

Las Nuevas Poblaciones de Sierra Morena y Andalucía nacieron a partir de 1767 como una jurisdicción independiente que tuvo como ley suprema el Fuero de 5 de

6 Nos consta que algún gobernante, como el superintendente Pablo de Olavide, empleó armas en los sellos con los que validaba la documentación más solemne que emitía (nombramientos de cargos, por ejemplo) pero no se trataba de las armas reales, que siempre fueron los símbolos propios de las nuevas colonias (Archivo Histórico Nacional -AHN-, Inquisición, leg. 3603, s.f.). También conocemos el uso por la Subprefectura de La Carolina, durante la primera derogación del Fuero de Sierra Morena entre 1810 y 1811, de un sello redondo con la cita SUBPREFECTURA CAROLINA con función clausora en la correspondencia oficial que ésta enviaba (Fig. 1). Más información en F. J. PÉREZ FERNÁNDEZ y C. SÁNCHEZ-BATALLA MARTÍNEZ, "La transformación de las comandancias civiles de Sierra Morena en municipalidades bajo dominio francés: el caso de Aldeaquemada", en Actas del IX congreso de cronistas de la provincia de Jaén, Jaén, 2012, p. 66. 
julio de $1767^{7}$. En un proceso gradual que se extendió hasta 1776 se le irían agregando una serie de territorios hasta formar dos grandes partidos territoriales: las Nuevas Poblaciones de Sierra Morena, con capital en La Carolina, y las Nuevas Poblaciones de Andalucía, con capital en La Carlota ${ }^{8}$. Una división que se trasladó también al plano gubernativo y de administración. De este modo, la Intendencia de las Nuevas Poblaciones de Sierra Morena y Andalucía se dividía en dos subdelegaciones ${ }^{9}$, las cuales ejercieron su autoridad en los mencionados partidos territoriales a las órdenes del intendente; a su vez, cada subdelegación estuvo integrada por varias feligresías o colonias que también tuvieron al frente, habitualmente, a un comandante civil para su gobierno. En cuanto a la administración, la autonomía de ambas subdelegaciones era muy amplia, tanto que en materia hacendística cada una dispuso de su propia Contaduría y se rendían cuentas al gobierno por separado.

La historiografía viene distinguiendo cuatro objetivos fundamentales para su puesta en marcha. En primer lugar, se aspiraba a poner en cultivo tierras hasta entonces baldías o poco aprovechadas, con lo que eso también implicaría de desarrollo para otros sectores asociados a cualquier núcleo poblacional, aumentando la riqueza del país. En segundo lugar, se pretendía aumentar la población útil con la entrada en los territorios de la Corona española de varios miles de labradores y artesanos extranjeros que se establecerían y generarían riqueza en esas tierras baldías. La protección de la principal vía de comunicación de la Península, la que unía Madrid con Cádiz y, por tanto, con los territorios americanos, constituyó el tercer gran objetivo de este proyecto colonizador. La apuesta por ese camino real a partir de 1761 dejó en evidencia que existían grandes extensiones en las que apenas podían verse algunas pequeñas ventas, por lo que se procuró prestarle protección y dotarlo de mejores servicios en esos tramos con la construcción de nuevos pueblos. Finalmente, el cuarto y último objetivo, muy ambicioso y compartido de facto solo por un reducido círculo de ilustrados, consistió en ensayar en esta colonización un modelo de sociedad agraria en la que no estuvieran presentes ciertos elementos del Antiguo Régimen que se consideraba entonces que suponían un freno para el desarrollo del Estado y que, por tanto, pudiera servir de referencia para aplicarse en otros lugares. A modo de ejemplo, podemos indicar que en las Nuevas Poblaciones de Sierra Morena y

\footnotetext{
Para profundizar en la historia de estas nuevas colonias es imprescindible la consulta de: C. ALCÁZAR MOLINA, Las colonias alemanas de Sierra Morena, Madrid, Universidad de Murcia, 1930; C. SÁNCHEZ-BATALLA MARTÍNEZ, La Carolina en el entorno de sus colonias gemelas y antiguas poblaciones de Sierra Morena. Prehistoria a 1835, Jaén, Caja Rural de Jaén, 1998-2003, 4 vols.; y A. HAMER FLORES, La Intendencia de las Nuevas Poblaciones de Sierra Morena y Andalucia (1784-1835). Gobierno y administración de un territorio foral a fines de la Edad Moderna, Córdoba, Universidad de Córdoba, 2009.

8 Las Nuevas Poblaciones de Sierra Morena estuvo integrada por los territorios de los actuales municipios jiennenses de Aldeaquemada, Santa Elena, La Carolina, Carboneros, Guarromán, Arquillos y Montizón; por su parte, las de Andalucía se conformaron con los de los municipios cordobeses de La Carlota, Fuente Palmera, Fuente Carreteros y San Sebastián de los Ballesteros y los sevillanos de La Luisiana y Cañada Rosal. Además, entre 1776 y 1799, una enorme extensión del término de Hornachuelos (Córdoba) también se integró en las Nuevas Poblaciones de Andalucía, siendo conocido como Sierra del Tardón.

9 Las nuevas colonias nacieron en 1767 como una Superintendencia, pero en 1784 se modificó su estructura de gobierno: la Superintendencia pasó a ser una Intendencia y aunque continuaban existiendo dos subdelegaciones, se optó por nombrar subdelegado solo en las Nuevas Poblaciones de Andalucía; en las de Sierra Morena el contador asumiría las funciones de subdelegado, lo que permitía que pudiera realizar las comisiones y trabajos que el intendente le encomendase y que lo sustituyese en sus ausencias y enfermedades. En las colonias de Andalucía, el contador podía ejercer esas mismas funciones cuando fuera necesario.
} 
Andalucía no estaba permitido el establecimiento de comunidades religiosas regulares, pagando la Real Hacienda los salarios de los sacerdotes y los gastos de culto de las iglesias; la instrucción primaria era obligatoria; los lotes de tierra no se podían acumular, dividir y menos aún amortizar al objeto de garantizar siempre que pudieran mantener con sus frutos una unidad familiar; y ningún empleo o cargo podía heredarse o enajenarse.

Como fundación promovida por la Corona, las armas propias de las colonias que integraban la Intendencia que aquí estudiamos eran las reales. En este sentido se pronuncian diversos autores de los siglos XVIII y XIX como Bernardo Espinalt, José Serrano de Rojas y Pascual Madoz. El primero de ellos, en su Atlante español editado entre 1778 y 1795, nos indica para el caso de las Nuevas Poblaciones de Sierra Morena que tienen "por armas las reales, que son: en escudo cuartelado dos castillos y dos leones contrapuestos" ${ }^{10}$ y para las Nuevas Poblaciones de Andalucía que "tienen por escudo de armas las reales" ${ }^{\prime 1}$. Por su parte, Serrano de Rojas, capellán mayor y vicario de las Nuevas Poblaciones de Andalucía, en las respuestas que dio en 1792 al interrogatorio del geógrafo Tomás López, afirma que La Carlota tenía "por armas las de Castilla y León" 12 . Finalmente, Madoz nos dice en su Diccionario GeográficoEstadístico-Histórico de España y sus posesiones de Ultramar, que vio la luz en Madrid entre 1845 y 1850, y donde solo incluye esporádicamente información relacionada con los escudos de las localidades, para la colonia de Fuente Palmera "tiene por escudo las armas reales"13. Aún más, la única nueva población que gestionó oficialmente el dotarse de un emblema municipal antes del siglo XX no tuvo mayor problema en que el gobierno autorizase con este objetivo el uso de las armas reales completas de Carlos III. Así pues, el Ayuntamiento de La Carolina viene usando desde marzo de 1883 ese escudo como propio ${ }^{14}$.

No debe extrañarnos, por tanto, que en las nuevas colonias fuese habitual situar las armas reales en edificios públicos de la Real Hacienda, incluidas las iglesias al haber sido erigidas a su costa y donde, al parecer, se situaban no solo en lugares habituales como la fachada o sobre la nave central ${ }^{15}$ sino hasta en las veletas ${ }^{16}$. En cambio, en lo concerniente a la documentación no nos consta su uso en ella hasta

10 B. ESPINALT Y GARCÍA, Atlante Español, o Descripción General Geográfica, Cronológica e Histórica de España, por Reynos y Provincias; de sus Ciudades, Villas y Lugares más famosos; de su Población, Ríos y Montes, \&c. Adornado de estampas finas que demuestran las vistas perspectiva de todas las Ciudades, trages propios de que usa cada Reyno y Blasones que les son peculiares, Madrid, 1787, tomo XIII, p. 96.

11 B. ESPINALT Y GARCÍA, Atlante Español..., tomo XI, p. 271.

12 Biblioteca Nacional de España (BNE), ms. 7294, f. 417v. Este informe está transcrito tanto en A. HAMER FLORES, "Las Nuevas Poblaciones de Andalucía a finales del siglo XVIII según el Diccionario GeográficoHistórico de Tomás López”, Ámbitos. Revista de Estudios de Ciencias Sociales y Humanidades, 14 (2005), pp. 97-98; como en C. SEGURA GRAÍÑO, Tomás López. Diccionario Geográfico de Andalucia: Córdoba, Córdoba, 2007, pp. 115-118.

13 P. MADOZ, Diccionario Geográfico-Estadístico-Histórico de Andalucía. Córdoba, Valladolid, 1987, p. 165.

14 Archivo Municipal de La Carolina, Jaén (AMLC), "Expediente instruido para conseguir de S.M. el rey (q.D.g.) la gracia del uso de maceros y de una medalla de plata pendiente de cordón del mismo metal para usarlo los concejales en los actos y festividades públicas".

15 A modo de ejemplo, en la iglesia de Fuente Palmera un escudo real de grandes dimensiones está situado en su fachada mientras que en el caso de La Carlota o La Carolina lo encontramos policromado en la nave central del templo dando paso al altar mayor.

16 De esta abundante presencia de las armas reales en edificios públicos e industriales patrocinados por la Real Hacienda en las nuevas colonias, extendida hasta las veletas de las iglesias -toda vez que todas ellas también eran propiedad de ese organismo-, nos informa en 1876 el alcalde de San Sebastián de los Ballesteros (AHN, Sigilografia, caja $\left.5, \mathrm{n}^{\circ} 57\right)$. 
1824. Será entonces cuando por vez primera aparezcan integradas dentro de los sellos que durante los años siguientes emplearán las autoridades neopoblacionales en sus documentos ${ }^{17}$.

Una corta etapa, pues apenas se extendió hasta la supresión del régimen foral de las nuevas colonias que tuvo lugar en marzo de 1835, que mostraría un contexto diferente al de otras anteriores. Este sistema de gobierno privilegiado sumaba con la vuelta al absolutismo de 1823 un total de tres restablecimientos, lo que implicaba otras tantas derogaciones en apenas trece años ${ }^{18}$, motivo por el que su pervivencia estaba entonces más ligada que nunca al favor real. Las voces que reclamaban su incorporación al régimen común del reino iban en aumento, de ahí que el intendente Pedro Polo de Alcocer ${ }^{19}$ desplegase durante todos esos años una intensa campaña para mostrar los beneficios de conservar el sistema foral. La piedra angular de toda su política sería el ambicioso plan de plantíos que propuso a Fernando VII en 1815 y que fue aprobado por éste el 25 de enero de ese año ${ }^{20}$.

El intendente realizaría una férrea defensa de su buen hacer y de la utilidad de ese sistema privilegiado, amparada siempre en la protección real. Ciertamente no podemos afirmar con seguridad que la creación de los sellos en tinta que aquí estudiamos estuviera vinculada con un deseo de mostrar ese carácter de jurisdicción bajo protección regia, pues no hemos podido localizar ningún testimonio documental que lo confirme; no obstante, es evidente que su elaboración y uso lo permitió. Además, en uno de los sellos incluso se visualizaría ese éxito de la iniciativa colonizadora mostrando tanto el cereal de tierra calma como los plantíos que se extendían por su territorio $^{21}$.

Ahora bien, el sello empleado por la Intendencia tuvo, paradójicamente, una corta vigencia según la documentación que hemos manejado ${ }^{22}$. Es probable que este hecho guarde relación con su uso como membrete, ya que cuando deja de aparecer en los documentos se observa que las fórmulas empleadas en dichos membretes manuscritos son extensas y detallan las competencias que tenía el intendente de las Nuevas Poblaciones. Frente a un sello en el que solo se identificaba a esa Intendencia, la fórmula manuscrita pudo ser entendida como más eficaz para Polo de Alcocer en la defensa de sus atribuciones gubernativas ${ }^{23}$. Una hipótesis que parece confirmarse

17 Estos sellos en tinta, una vez derogado el sistema foral, no tendrían continuidad en los elaborados por los diferentes ayuntamientos que se establecieron en estas nuevas colonias salvo por el uso de las armas del Estado del modo en que lo hacían otros municipios, armas con las que pudieron llegar a identificar su origen de realengo. La única excepción fue el municipio de Montizón (Jaén), que reivindicó su origen como nueva población incluyendo en el campo la leyenda "N.P.D. / SIERRA / MORENA" (AHN, Sigilografia, cajas 5, 8 y 16).

18 La primera supresión fue realizada en mayo de 1810 por el gobierno de José I Bonaparte, mientras que las otras dos fueron iniciativa de las Cortes Constitucionales en marzo de 1813 y junio de 1820 .

19 Polo de Alcocer ocupó el cargo de intendente de las Nuevas Poblaciones de Sierra Morena y Andalucía en dos etapas: $1814-1820$ y $1823-1835$.

20 A. HAMER FLORES (ed.), Legislación Histórica Neopoblacional. Disposiciones normativas emanadas del poder central en las Nuevas Poblaciones de Sierra Morena y Andalucía (1767-1835), Madrid, 2018, pp. 155156.

21 Nos referimos al sello de la Subdelegación de las Nuevas Poblaciones de Andalucía.

22 Las grandes lagunas documentales nos impiden afirmar con seguridad que dejara de utilizarse, ya que pudo seguir empleándose en ocasiones concretas hasta la supresión del sistema foral. Dejando de lado casos puntuales, los archivos que nos han facilitado mayor número de ejemplos de sellos en tinta han sido el Archivo Municipal de Aldeaquemada (Jaén), el Archivo Municipal de La Carolina (Jaén), el Archivo Histórico Provincial de Jaén, el Archivo Municipal de Fuente Palmera (Córdoba) y el Archivo Notarial de Posadas (Córdoba).

23 El que este sello en tinta deje de aparecer en la documentación que hemos manejado no implica necesariamente que dejara de usarse por completo. No descartamos que pudiera seguir estampándose de manera puntual en 
con lo sucedido en el caso del sello de la Subdelegación de las Nuevas Poblaciones de Andalucía pues, aunque en ocasiones se usaría indistintamente con la fórmula del membrete manuscrito, se mantiene en uso hasta 1835. Al ser una subdivisión de la Intendencia de las Nuevas Poblaciones, la defensa de esas competencias no recaía directamente en este subdelegado y no era necesario en su caso usar fórmulas complejas en los membretes.

\section{Los sellos en tinta utilizados en las Nuevas Poblaciones de Sierra Morena y Andalucía}

En un principio el uso de los sellos se restringía a los documentos más solemnes, pero la práctica aduanera comenzó a extender el uso de sellos en tinta para el marchamo de las mercancías que habían devengado los derechos arancelarios correspondientes. En el siglo XIX, especialmente vinculado a la consolidación del estado liberal, se extendería el uso del sello como consecuencia de la regulación estatal de procedimientos administrativos y económico-administrativos. Una generalización que vino precedida, y a la par fue coetánea, del afianzamiento del uso del membrete en los actos administrativos ${ }^{24}$.

Las Nuevas Poblaciones no fueron ajenas a este fenómeno. Dejando de lado los únicos membretes impresos localizados, que se utilizaron en contextos en los que no estaba vigente el Fuero de las Nuevas Poblaciones ${ }^{25} \mathrm{o}$ formaban parte de la estructura de Policía articulada a partir de $1824^{26}$, constatamos que el uso de membretes manuscritos solo se normalizó después del Trienio Liberal. La Intendencia utilizaría la fórmula manuscrita "Intendencia y Gobierno Directivo de Nuevas Poblaciones", con alguna variante como emplear los términos "Privativo" o "Civil y Político" en lugar de "Directivo" "27. Por su parte, la Subdelegación de La Carlota haría uso de la fórmula "Subdelegación y Gobierno de las Poblaciones de Andalucía"28.

Durante los últimos años de vigencia del Fuero de las Nuevas Poblaciones nos consta el uso de cuatro sellos en tinta en su documentación: el de la Intendencia de Nuevas Poblaciones (Fig. 2), el de la Subdelegación de las Nuevas Poblaciones de Andalucía (Fig. 3), el de la Contaduría de Sierra Morena (Fig. 4) y el de la Coman-

documentos internos o en los dirigidos a personajes u organismos ante los que no era necesario explicitar todas esas competencias.

24 Los símbolos de la Hacienda Pública, Madrid, 2006, p. 93.

25 Este fue el caso del membrete utilizado en la documentación emanada de la Subjefatura de las Nuevas Poblaciones de Sierra Morena establecida en la provincia de Jaén tras la supresión de su régimen foral en 1820. Hemos localizado dos membretes: el primero incluía en versalitas la inscripción: "SUBGEFATURA DE LA PROVINCIA / DE JAÉN EN LAS NUEVAS / POBLACIONES DE SIERRAMORENA", mientras que el segundo indicaba: "GOBIERnO Político Subalterno / De LAs Nuevas Poblaciones" (Archivo Municipal de Aldeaquemada, Jaén -AMA-, caja 23). Una vez derogado el Fuero en 1835, el organismo encargado de la administración de las rentas de las colonias de Sierra Morena utiliza el siguiente membrete: "ADMINISTRACIÓN DE RENTAS / NACIONALES / DE LAS POBLACIONES DE LA CAROLINA" (AMA, caja 25).

26 La Superintendencia General de Policía estableció en el partido de La Carolina una subdelegación de policía dependiente de la Intendencia de Policía de Jaén. No nos consta que esta subdelegación utilizase sello en tinta pero sí que manejaba oficios con membrete impreso con la inscripción: "SUBDELEGACION DE POLICIA / de la / REAL CAROLINA" (AMA, caja 24).

27 AMA, cajas 24 y 25.

28 Archivo Municipal de Fuente Palmera, Córdoba (AMFP), Comandancia de Fuente Palmera, tomos III y IV. 
dancia civil de La Luisiana (Fig. 5). Los tres primeros fueron elaborados expresamente para esta finalidad, mientras que el cuarto sospechamos que fue resultado de la modificación de un sello empleado anteriormente por las autoridades constitucionales de La Luisiana durante el Trienio Liberal.

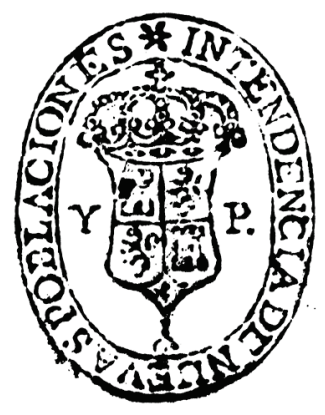

Figura 2. Sello en tinta de la Intendencia de Nuevas Poblaciones, año 1824 (AMA, caja 23).

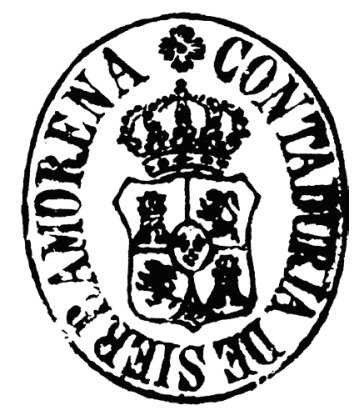

Figura 4. Sello en tinta de la Contaduría de Sierra Morena, año 1825 (AMA, caja 23).

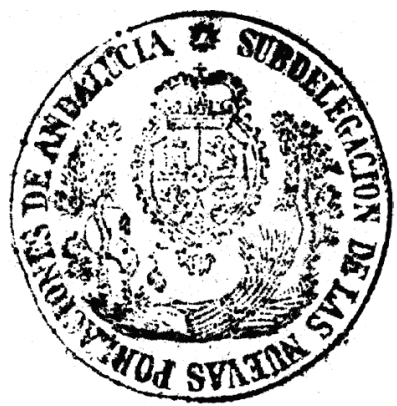

Figura 3. Sello en tinta de la Subdelegación de las Nuevas Poblaciones de Andalucía, año 1835 (ANPO, $L a$ Carlota, Escribano Miguel Muñoz, prot. 919, año 1835, f. 97r).

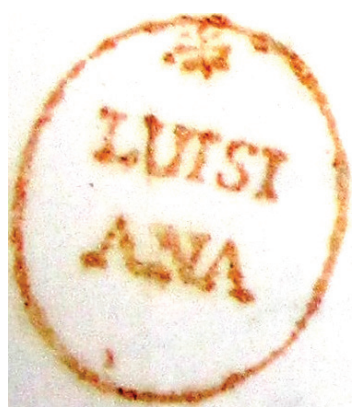

Figura 5. Sello en tinta de la Comandancia civil de La Luisiana, año 1826 (ANPO, $L a$ Carlota, Escribano Miguel Muñoz, prot. 905, año 1826, f. 223r).

Teniendo en cuenta que se trata de fechas provisionales por las enormes pérdidas documentales, ya mencionadas, que han sufrido los archivos con documentación gubernativa y administrativa de las nuevas colonias, hemos podido hallar unas fechas extremas en el uso de estos sellos. Los primeros en introducirse fueron los de la Intendencia de Nuevas Poblaciones y la Contaduría de Sierra Morena, constatado el primero entre 1824 y 1826 y el segundo entre 1825 y 1834 ; el correspondiente a la Comandancia civil de La Luisiana lo hemos localizado en el año 1826 (aunque pro- 
bablemente su uso fuera extensivo a casi toda la Década Absolutista); y el correspondiente a la Subdelegación de las Nuevas Poblaciones de Andalucía se comienza a usar en 1827, empleándose hasta 1835.

Se trata de sellos que identifican a los principales cargos de gobierno y administración de las nuevas colonias. El de la Intendencia por ser la máxima autoridad en ellas y los de la Subdelegación de las Nuevas Poblaciones de Andalucía y la Contaduría de Sierra Morena por corresponderse con la autoridad inmediatamente inferior al intendente en cada partido territorial. Como indicábamos anteriormente, a partir de 1784 la Contaduría de Sierra Morena asumió las funciones que había tenido hasta entonces el subdelegado de las Nuevas Poblaciones de Sierra Morena, pasando a ser denominado su titular como contador-subdelegado de Sierra Morena. De ahí que éste pudiera usar también el sello de la Contaduría para los asuntos que atendiese como subdelegado del intendente. Por su parte, en las Nuevas Poblaciones de Andalucía, al estar estos empleos en dos personas distintas, cuando el contador actuaba por indicación del subdelegado estampaba en sus oficios el sello de la Subdelegación de las Nuevas Poblaciones de Andalucía y firmaba anteponiendo la leyenda PDDSS ${ }^{29}$.

En otro orden de cosas, nos consta que también se hizo uso en La Carlota en la etapa que estudiamos del sello de la Subdelegación de Policía de La Carlota, aunque no lo analizaremos aquí. En este caso nos encontramos ante una competencia delegada de la Intendencia de Policía de Córdoba, por lo que ese sello en tinta sería decidido por este último organismo. La real cédula de 13 de enero de 1824 creó la Superintendencia General de Policía, que establecerá una estructura en la que a nivel de provincia existirá un intendente de Policía y en cada uno de los partidos que dependían de ella un subdelegado de Policía. En esta ocasión, por motivos que desconocemos, pero que tal vez buscaron ahorrar costes, el gobierno optó por no considerar la Intendencia de las Nuevas Poblaciones como una Intendencia de Policía, por lo que en esta materia pasaron a depender de los intendentes de Jaén y Córdoba; en cualquier caso, tanto en La Carolina como en La Carlota hubo una subdelegación de Policía, ejerciendo como subdelegados en este ramo el intendente en La Carolina y su subdelegado en La Carlota. Con el tiempo fueron necesarias algunas reformas de este decreto plasmadas en el real decreto de 14 de agosto de 1827, pero años más tarde se consideró que era más beneficioso volver a lo dispuesto en 1824, por lo que se dispuso la derogación del promulgado en 1827 a través del real decreto de Fernando VII de 25 de septiembre de 1833.

\subsection{Aspectos externos}

En lo que respecta a la forma exterior de los sellos en tinta el formato preferido fue el oval (Intendencia de Nuevas Poblaciones, Contaduría de Sierra Morena y Comandancia civil de La Luisiana), empleándose el circular solo en un caso y quizá por la abundancia y complejidad de los elementos representados (Subdelegación de las Nuevas Poblaciones de Andalucía). Todos los ejemplos analizados se corresponden con la tipología de impresos en tinta.

29 Por Delegación del Señor Subdelegado. 
La dimensión de los sellos ovales era similar a la empleada entonces por otras administraciones; no así la del sello circular de la Subdelegación, pues ocupaba gran parte del espacio que habitualmente se reservaba como margen izquierdo en los oficios. Finalmente, en relación con el color de la tinta utilizada, el color predominante era el negro; siendo el único tono empleado en los sellos de la Intendencia de Nuevas Poblaciones y en el de la Contaduría de Sierra Morena, y el mayoritario en el de la Subdelegación de las Nuevas Poblaciones de Andalucía. Este último fue estampado en alguna ocasión en color ocre o anaranjado al igual que el único ejemplo que hemos podido localizar del sello de la Comandancia civil de La Luisiana ${ }^{30}$.

\subsection{Aspectos internos}

En el campo de los sellos estudiados, a excepción del empleado por la Comandancia civil de La Luisiana, aparecen siempre las armas reales en versión reducida. En el caso de los correspondientes a la Intendencia de Nuevas Poblaciones y a la Contaduría de Sierra Morena es casi el único mueble incluido, mientras que en el de la Subdelegación de las Nuevas Poblaciones de Andalucía es acompañado por otros elementos. El escudo real aparece representado de diversos modos: Contaduría (escudo de piel de toro o casulla cuartelado con cuarteles de Castilla y León, sobre los que se superpone el escusón de la dinastía reinante Borbón, y entado en punta el blasón de Granada; timbrado con la corona real cerrada), Intendencia (escudo de piel de toro o casulla, con parte superior curvilínea hacia el centro, cuartelado con cuarteles de Castilla y León y entado en punta el blasón de Granada; timbrado con la corona real cerrada y con el carnero de toisón de oro colgando de la punta inferior) y Subdelegación (escudo de piel de toro o casulla cuartelado con cuarteles de Castilla y León, sobre los que se superpone el escusón de la dinastía reinante Borbón, y entado en punta el blasón de Granada; timbrado con corona real cerrada y orlado con el toisón de oro). Diferencias que muy probablemente se deban a haberse confeccionado en momentos y por artífices diferentes.

El sello de la Intendencia incluye, además, en el campo dos elementos de naturaleza epigráfica. Se trata de dos letras, una a cada lado del escudo real correspondientes a las iniciales del nombre institucional de esta intendencia: Y(ntendencia de Nuevas) P(oblaciones). Por su parte, el sello de la Subdelegación suma, como indicábamos, más muebles, adquiriendo una distribución muy similar a la de algunos sellos incluidos en el papel sellado y en las monedas con las columnas de Hércules de las colonias americanas ya desde el siglo XVII ${ }^{31}$. El escudo real se sitúa en la parte superior, estando flanqueado a derecha e izquierda por sendos arboles (probablemente olivos de corta edad) de factura diferente plantados en un terreno sobre el que puede verse una gavilla de cereal. Junto al árbol situado a la derecha de las armas reales parece intuirse un olivo de corta edad o una viña. Elementos todos ellos estrechamente relacionados con el carácter de colonización agraria de estas nuevas colonias. La mencionada gavilla de cereal da buena cuenta de ello, pero la presencia de

\footnotetext{
30 Este color no parece resultado de algún proceso degenerativo de la tinta. Este proceso degenerativo sí lo hemos constatado para algunos sellos de color negro, que han adquirido tonalidades verdosas.

31 L. PERALTA, El papel sellado en el Perú colonial, 1640-1824, Lima, 2007, pp. 127-128.
} 
los plantíos lo refuerza al estar en conexión directa con el decidido impulso que se dio a partir de 1815 a este cultivo.

Por último, el sello de la Comandancia civil de La Luisiana presenta en su campo, en dos líneas, únicamente la cita: LUISI / ANA; se trata, por tanto, de un ejemplo afigurativo que solo expresa el nombre de la localidad. La similitud de este ejemplo con muchos otros sellos elaborados en localidades cercanas, e incluso en las propias colonias, durante el Trienio Liberal para sus ayuntamientos constitucionales nos pone en la pista de que su origen también debió estar en esa época ${ }^{32}$. No obstante, suprimido ese Ayuntamiento Constitucional de La Luisiana y reimplantada la Comandancia Civil en 1823, alguien debió considerar la posibilidad de reutilizar ese sello eliminando la leyenda circular ${ }^{33}$, con lo que se podría disponer sin ningún coste de un elemento validativo para la documentación.

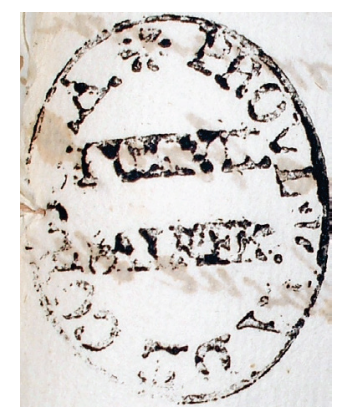

Figura 6. Sello en tinta del Ayuntamiento Constitucional de Fuente Palmera, año 1822 (AHPCO, Protocolos de Guadalcázar, caja 5997P).

Al margen del campo, en los tres primeros casos estudiados se identifica al organismo en la leyenda circular que lo circunscribe. En el de la Intendencia se puede leer: INTENDENCIA DE NUEVAS POBLACIONES; en el de la Subdelegación: SUBDELEGACION DE LAS NUEVAS POBLACIONES DE ANDALUCIA; y en el de la Contaduría de La Carolina: CONTADURIA DE SIERRA MORENA. Mientras que en dos de los casos se inicia con una estrella en la parte superior, lugar éste en el que también concluye el texto, en el tercero parece ser una cruz patada ${ }^{34}$. Para su redacción se utilizan siempre grafías mayúsculas y nunca aparecen elementos que actuasen de separador de palabras. Otro elemento para señalar en la inscripción es que en los casos de la Intendencia y de la Contaduría discurre dentro de la orla entre gráfilas, siendo una de ellas la exterior del sello; pero en el caso del de la Subdelegación solo posee gráfila exterior.

32 En las propias Nuevas Poblaciones conocemos el caso de un sello en tinta muy similar empleado por el Ayuntamiento de Fuente Palmera en 1822 (Archivo Histórico Provincial de Córdoba -AHPCO-, Protocolos de Guadalcázar, caja 5997P). Véase la Fig. 6.

33 Es probable que el texto de esta leyenda circular fuera: PROVINCIA DE SEVILLA.

34 En el caso de la Intendencia la estrella tiene una forma casi de flor con seis trazos que parten de un punto central, mientras que en el caso de la Subdelegación se corresponde con una estrella de ocho puntas o de Salomón (resultado de la superposición de dos cuadrados concéntricos, uno de los cuales ha sido girado 45 grados). En lo que respecta al sello de la Contaduría, nos encontramos ante un diseño floral que trata de imitar una cruz griega o patada. 
En cuanto al sello de la Comandancia Civil de La Luisiana es diferente, al carecer de leyenda circular, por los motivos que ya hemos expuesto; incluye tan solo la cruz griega o patada que sirvió de inicio y final de la inscripción que incluyó en su origen, así como la gráfila exterior que la acompañaba.

\subsection{Función sigilar}

Los sellos de las nuevas colonias se utilizaron, principalmente, con dos funciones: notoria o identificativa y validativa. No nos consta que se emplease ningún sello con función clausora en la documentación de la etapa foral, limitándose a cerrar con lacre el pliego que se utilizaba como sobre.

Los sellos notorios o identificativos suelen aparecer en la parte superior del documento, careciendo de función validativa. En el caso que nos ocupa, tanto el sello de la Intendencia de Nuevas Poblaciones como el de su Subdelegación de las Nuevas Poblaciones de Andalucía se estampan siempre en la parte superior izquierda del pliego, haciendo las veces de membrete. No nos ha sido posible constatar ningún caso en el que se combinen sellos y anotaciones manuscritas.

El sello de carácter validativo se ubica al final del documento formando parte de los demás elementos autenticadores de éste, básicamente la firma y rúbrica, a los que no sustituía en ningún caso, sino que los complementaba. En el caso que estudiamos, el sello de la Contaduría de Sierra Morena, aunque en alguna ocasión parece tener una función identificativa, en la mayor parte de los casos estudiados se estampa en diferentes lugares del pliego, que van desde la parte superior hasta la inferior pasando por el margen. Su intención en esas ocasiones es claramente validativa aunque no siempre se sitúe al final, especialmente en los documentos completamente manuscritos. Quizá se consideró innecesario emplearlo en los formularios impresos por contener estos ya ese elemento que le confería autenticidad. El caso del sello de la comandancia civil de La Luisiana se corresponde también con esa intención validativa.

\section{Conclusiones}

A lo largo de los apartados anteriores hemos podido comprobar que el uso de sellos en tinta en la Intendencia de las Nuevas Poblaciones de Sierra Morena y Andalucía solo estuvo vinculada a la última etapa de vigencia de su régimen foral. Coincidiendo con una generalización en la administración en el uso de membretes y elementos que identificasen a los remitentes de los documentos, también las nuevas colonias implantaron durante la última etapa de gobierno del intendente Pedro Polo de Alcocer el uso de esos membretes y se dotaron de varios sellos identificativos para sus organismos principales (Intendencia de Nuevas Poblaciones, Subdelegación de las Nuevas Poblaciones de Andalucía y Contaduría de Sierra Morena).

Unos sellos en tinta que, aunque rara vez tuvieron una intención validativa, siendo predominantemente identificativos al sustituir al membrete, consideramos que se implantaron con el deseo de marcar la autonomía jurisdiccional de estas nuevas colonias frente a otras autoridades y de evidenciar su carácter de fundación real protegida 
directamente por el monarca; siendo muy útil para ello la inclusión de las armas reales. Una intención que, al parecer, pudo verse frustrada en el caso del sello de la Intendencia de Nuevas Poblaciones, pues no nos ha sido posible localizar ningún ejemplo posterior a 1826, lo que parece indicar que el intendente optó a partir de entonces por detallar minuciosamente a mano sus competencias en los membretes de los oficios.

El diseño de estos sellos fue en la línea de otros empleados en la época estudiada, de ahí que se limitaran a incluir las armas reales y a identificar el organismo al que pertenecían. No obstante, en el caso del correspondiente a la Subdelegación de las Nuevas Poblaciones de Andalucía, último en elaborarse, podemos ver un interesante despliegue de elementos que permitían no solo remarcar el carácter real de la fundación sino también mostrar que se trataba de una colonia agraria gracias a la inclusión de los principales elementos en los que se apoyaba su riqueza (cereal y plantíos de olivar). 